\title{
DYNAMIC MECHANICAL PROPERTIES OF CROSSLINKED NATURAL RUBBER COMPOSITES REINFORCED WITH CELLULOSIC NANOPARTICLES
}

\author{
J. O. Oboh ${ }^{1, *}$, J. O. Okafor ${ }^{2}$, A. S. Kovo ${ }^{3}$ and A. S. Abdulrahman ${ }^{4}$ \\ 1,3, Department of Chemical EngineERING, FEDERAl UniVersity of TeChNOLOGy MinNa, Niger State, NigERIA. \\ 2, DEPT. OF POLYMER TECH., NigERIAN INSTITUTE OF LEATHER AND SCI. TECH, ZARIA, KADUNA STATE, NIGERIA. \\ 4, Dept. of Material and Metallurgical Engineering, Fed. Univ. of TeCh., Minna, Niger State, Nigeria. \\ E-mail addresses:1 labconsult@yahoo.com, ${ }^{2}$ jookai2003@yahoo.com,33ovoabdulsalami@gmail.com, \\ 4 asipita.salawu@futminna.edu.ng.
}

\begin{abstract}
The dynamic mechanical analysis (DMA) of crosslinked natural rubber nanocomposites reinforced with cellulosic nanoparticles obtained from lignocelluloses biomass (coconut husk, bamboo culm and cotton linters) has been investigated and compared with carbon black filled natural rubber vulcanizate. The crosslinked natural rubber matrix based composites were produced by melt intercalation process using two roll mixing mill and vulcanized in a thermally regulated hydraulic press. DMA were carried out in order to obtain their viscoelastic thermo-mechanical spectrum. Results showed decrease in storage modulus ( $\left.E^{\prime}\right)$ with increasing temperature while glass transition temperatures (Tg) obtained from temperature dependence loss tangent curves were $-35.84,37.30,-34.61,-35.27$ and $-34.29{ }^{\circ} \mathrm{C}$ for neat- natural rubber (NR), natural rubber reinforced carbon black (NR-CB), natural rubber reinforced bamboo cellulosic particles (NR-BNC), natural rubber reinforced coconut husk cellulosic particles (NR-CHNC) and natural rubber reinforced cotton linter particles (NR-CLNC) respectively. The composite of NR-CHNC was also found to give a higher damping factor of 1.563 compared to $N R-C B$ which gave a value of 1.518. nanocomposites reinforced with cellulosic nanoparticles can provide adequate synergy for loading bearing and vibration isolation application.
\end{abstract}

Keywords: Dynamic Mechanical Properties; Damping; Nanocomposites; Grass Transition Temperature.

\section{INTRODUCTION}

The increasing concern about global warming and depleting petroleum reserves have led to considerable interests in developing green nanocomposites in industrial and technological space owing to their renewability and sustainability, biodegradability and environmental friendliness [1 - 3]. Natural rubber, in its raw state is not suitable for use in any given application because of its viscoelasticity. This viscoelastic tendency gives rise to creep, a tendency of solid material to move slowly or deform permanently under the influence of thermal and mechanical stresses. This behaviour is adverse to engineering and other applications. In addition, raw rubber does not possess the required yield strength for any meaningful application. Hence it is usually reinforced. The rubber industries presently rely on carbon black as its main source of rubber reinforcement. This same carbon black is obtained as a by-product of petroleum which is an exhaustible source.
Dynamic mechanical analysis (DMA) is an important technique used to indicate molecular relaxation dynamics of polymeric materials [4-5]. The principle of DMA measurement is such that, a sinusoidal stress is applied and the corresponding strain in the material is evaluated, allowing one to determine the storage modulus, loss modulus and loss tangent or damping Factor. By studying the dependence of these parameters on temperature or frequency, it is possible to show the dynamic mechanical properties (such as thermodynamic transitions and other molecular relaxation) of the materials and their applications [5, 6]. The vulcanization of natural rubber inserts three dimensional crosslink network structures into rubber matrix that will lead to decrease in its chain mobility and conformational entropy [7-8]. Hence, the result of this structural change is usually a positive shift in the glass transition temperature ( $\mathrm{Tg}$ ) of raw rubber [9-10]. Similarly, the introduction of reinforcing agents into the rubber matrix can introduce some sorts of physical

* Corresponding author tel:, +234-803- -506- 0872 
crosslinks into the rubber matrix thereby increasing the overall crosslink network structure of the vulcanizates. These physical crosslinks can alter the conformational entropy, chain mobility and free volume that are associated with viscoelatic transitions $[11,12]$. Visakh et al. [10] reported an increase in the storage modulus of natural rubber composite reinforced with $10 \%$ wt bamboo based cellulosic nanowhisker and a shift in temperature of Tan max from $-47^{\circ} \mathrm{C}$ to $-42{ }^{\circ} \mathrm{C}$. The objective of this study is to investigate the dependence of dynamic mechanical properties on cellulosic nanoparticles types (coconut husk, bamboo and cotton linter) as well as carbon black inclusion in vulcanized rubber matrix.

\section{MATERIALS AND METHODS}

\subsection{Materials}

The materials used for this experiment were dry natural rubber, carbon black, stearic acid, mercaptobenzothiazoledisulfide (MBTS), trimethylquinolone (TMQ), and zinc oxide and were supplied by Tony West rubber factory, Lagos Nigeria. The specifications of the dry natural rubber according to the supplier were $\leq 0.05 \%$ dirt content, $\leq 1.00 \%$ volatile content, $\leq 0.7 \%$ nitrogen content, $\leq 0.6 \%$ ash content, minimum of 30 initial plasticity, minimum of 60 plasticity retention index (PRI) and blackish brown in colour. The carbon black was of N330 grade and was manufactured by Warri Refinery and Petrochemical, a subsidiary of Nigerian National Petroleum Corporation (NNPC) with particle size distribution of 50 to $500 \mathrm{~nm}$. Other compounding ingredients were of rubber processing commercial grade and used as received. The cellulosic particles obtained from treated biomass through mechanical process were used as reinforcing filler and they were of particle size distributions of 32 $175,68-311$ and 620 to $5408 \mathrm{~nm}$ for bamboo, coconut husk and cotton linter sources respectively[13].

\subsection{Methods}

\subsubsection{Preparation of Samples}

The method employed in development and measurement of cellulosic nanoparticles from bamboo, coconut husk and cotton linter has been reported in our previous study [13]. Twenty five (25) parts per hundred rubber (pphr) of reinforcing fillers namely carbon black (CB), cellulosic particles of bamboo (BNC), coconut husk (CHNC) and cotton linters (CLNC) were used for the purpose of this research. The rubber composite samples were prepared through melt intercalation process using two roll mixing mill. The mixing/compounding of the rubber with the various reinforcement agents and other ingredients such as the vulcanizing and protective agents were carried out in two roll mixing mill at a temperature of $65 \pm 5{ }^{\circ} \mathrm{C}$ and friction speed of ratio of 1.25:1 for about 15 minutes of mixing circle. This process was followed by In-situ moulding/vulcanization of test samples using compression moulding process at a temperature of 145 ${ }^{\circ} \mathrm{C}$ for 13 minutes each. The formulation used is shown in Table 1.

Some basic physical properties of samples such as tensile strength, modulus at 100 and $300 \%$ elongation at break (ASTM D412) and shore A hardness (ASTMD 2240) were also evaluated in accordance with America Society for Testing Materials [13].

\subsection{Dynamic Mechanical Measurements}

The dynamic mechanical analysis of test piece was carried out using TA instrument (DMA Q800). Samples were moulded to specimen dimension of $35 \times 8 \times 3 \mathrm{~mm}$. The samples were tested using tension mode. Prior to the test, samples and fixture were cooled from ambient to $-100{ }^{\circ} \mathrm{C}$ using liquid nitrogen. On commencement of the test, the temperature was increased at the rate of 3 ${ }^{\circ} \mathrm{C} / \mathrm{min}$. Samples were sinusoidally loaded at a frequency of $1 \mathrm{~Hz}$ at an amplitude of $15 \mu \mathrm{m}$ using temperature sweep mode from -90 to $+90{ }^{\circ} \mathrm{C}$. During the test the viscoelastic spectrum (storage modulus E', loss modulus E" and tangent loss factor E"/E') were recorded as a function of temperature.

\section{RESULTS AND DISCUSSIONS}

\subsection{Physical Properties of Composites}

The tensile strength, modulus and hardness (Shore A) of various samples are shown in Table 2. The composite of coconut husk showed superior properties (NR-CHCN) in all cases.

The general improvement on the physical properties of cellulosic particle based composites (NR-CHNC, NRBNC and NR-CLNC) over that of reference sample (neat $\mathrm{NR}$ ) and their competiveness with standard carbon black based composites (NR-CB) was due to the nanometric characteristics of the cellulosic particles [14-15].

\subsection{Effect of Temperature and Filler Types on Storage Modulus}

The effect of temperature on storage modulus of a reference neat-NR, NR-CHNC, NR-BNC, NR-CLNC and NR-CB composites are shown in Figure 1. The storage modulus measures the stiffness and stored energy; representing the elastic region of viscoelastic materials [6]. 
Dynamic Mechanical Properties of Crosslinked Natural Rubber Composites Reinforced with Cellulosic ..., J. O. Oboh, et al.

Table 1: Formulation for crosslinked rubber composites (Pphr)

\begin{tabular}{llllll}
\hline Sample & Neat NR & NR-CB & NR-BNC & NR-CHNC & NR-CLNC \\
\hline NR & 100 & 100 & 100 & 100 & 100 \\
Zinc oxide & 5 & 5 & 5 & 5 & 5 \\
Stearic acid & 2 & 2 & 2 & 2 & 2 \\
Reinforcing filler & - & 25 & 25 & 25 & 25 \\
TMQ & 1 & 1 & 1 & 1 & 1 \\
MBTS & 2 & 2 & 2 & 2 & 2 \\
Sulphur & 3 & 3 & 3 & 3 & 3 \\
\hline
\end{tabular}

$N R=$ natural rubber, $T M Q=$ trimethylquinolone, $M B T S=$ mercaptobenzothiazoledisulfide, $N R-C B=$ natural rubber-carbon black, $N R$ - BNC = natural rubber-bamboo cellulosic particles, $N R$-CHNC = natural rubber-coconut husk cellulosic particles, NR-CLNC = natural rubber-cotton lint cellulosic particles.

Table 2: Properties Composites

\begin{tabular}{llllll}
\hline Sample & Neat NR & NR-CB & NR-BNC & NR-CHNC & NR-CLNC \\
\hline Tensile strength (MPa) & 1.85 & 3.36 & 2.82 & 3.82 & 2.63 \\
Modulus at 100\% (MPa) & 0.50 & 0.90 & 1.00 & 1.00 & 0.80 \\
Modulus at 300\% (MPa) & 0.30 & 0.70 & 0.60 & 0.70 & 0.50 \\
Shore A hardness & 41 & 50 & 55 & 60 & 56 \\
Elongation at break (\%) & 552 & 497 & 502 & 670 & 535 \\
\hline
\end{tabular}

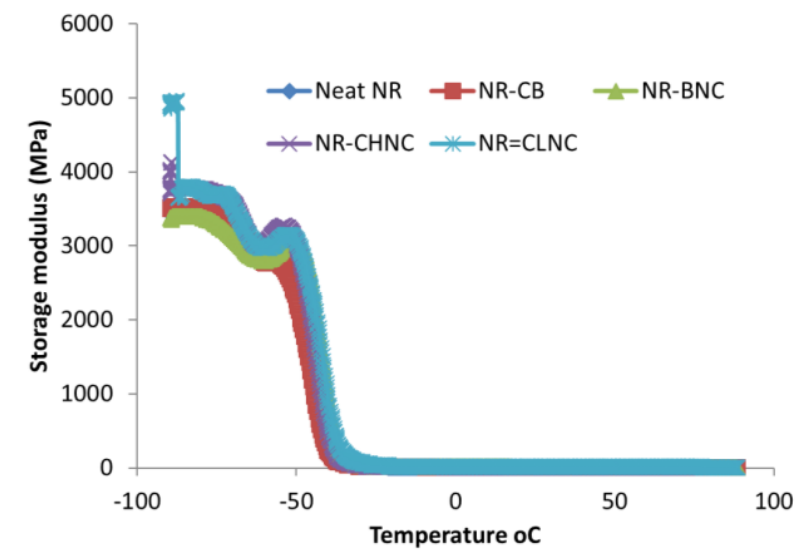

Figure 1: Effect of Temperature on the Storage Modulus of Composites

The results showed general decrease in storage modulus with increasing temperature (from - 90 to + $100{ }^{\circ} \mathrm{C}$ ) for all samples. However, there was appearance of hunchbacks (sudden stiffening of the composites sample) on storage modulus versus temperature curves for cellulosic particles based composites (NRCHNC, NR-BNC, NR-CLNC) around temperatures of -50 ${ }^{\circ} \mathrm{C}$. This could be attributed to molecular relaxation occurring in cellulosic components of the composites. The values of storage modulus obtained at $-70{ }^{\circ} \mathrm{C}$ were 3254, 3619, 3125, 3600 and $3257 \mathrm{MPa}$ for a reference neat-NR, NR-CHNC, NR-BNC, NR-CLNC and NR-CB respectively while their corresponding values at $+20{ }^{\circ} \mathrm{C}$ were 2.08, 3.13, 4.58, 6.72 and 2.78 MPa. Similar to the results of physical properties (see Table 2), NR-CHNC gave the highest storage modulus at $-70{ }^{\circ} \mathrm{C}$, also, at temperature of $+20{ }^{\circ} \mathrm{C}$, cellulosic based composites showed superior storage modulus over neat NR and standard NR-CB. These values are very similar to the ones obtained by Visakh et al. [10] and Zhang et al. [16]. In the context of this work, CHNC, BNC and CLNC are cellulosic particles obtained from coconut husk, bamboo and cotton linters respectively through the same procedure; hence, the same level of reinforcements were expected to be conferred on the rubber matrix. However, this was not the case as seen in the values earlier presented. Therefore, the difference in their level of reinforcements conferred on the rubber matrix could be due to the varying ratio of alpha- cellulose to beta- cellulose in the various biomass [17]. The general decrease in storage modulus with increasing temperature is theoretically expected for all samples. This can be explained using chain mobility theory [4], thus increase in temperature will lead to increase in enthalpy of composite chain, hence much internal energy will be made available to be used for weakening or destroying the physical bonds and entanglements associated with the polymer chains. Again, upon heating less energy will be stored since the molecular chains will move with force, thereby giving a decline in storage modulus. 


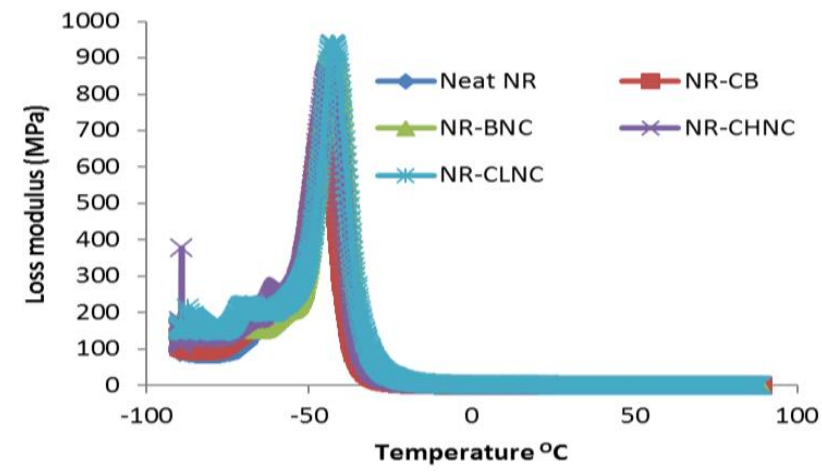

Figure 2: Effect of Temperature on Loss Modulus of Composites

\subsection{Effect of Temperature and Particle Types on Loss Modulus}

The effect of temperature on loss modulus of neat-NR, NR-CHNC, NR-BNC, NR-CLNC and NR-CB composites are shown in Figure 2. Loss modulus represents the viscous region of a viscoelastic material. It is simply the measure of energy dissipated as heat during vibration or loading cycle of the material [18]. Similar bellshaped curves were observed for all composite samples characterized with major peaks in the neighborhood of $-50{ }^{\circ} \mathrm{C}$; such that, there was an initial increase in loss modulus with increasing temperature up to a point after which further increase in temperature resulted to a corresponding decrease in loss modulus. This point of inflection is sometimes used to locate the glass transition temperature (see Table 3) since it gives the physical manifestation of glass transition temperature, however, the loss tangent or damping factor, is often used to locate glass transition temperature because of its sharpened emphasis.

The best way to interpret this curve is to view it as force versus energy dissipation rather than modulus versus temperature, thus upon initial heating, though the material will be less stiff, more force will be dissipated as heat, increasing the loss modulus. As temperature continues to increase above a critical point as a result of further heating, there will be reduction in molecular friction and hence less energy will be dissipated leading to a decrease in loss modulus [19]. Cellulosic particle based composites (NR-CHNC, NR-BNC and NR-CLNC) were observed to give secondary peaks at temperatures below the inflection points of the various curves. These secondary peaks could be attributed to molecular relaxation of cellulose component of the composites [5], since these peaks were only associated with cellulosic particle based composites and they coincided with the hunchbacks observed in the storage modulus versus temperature curves.

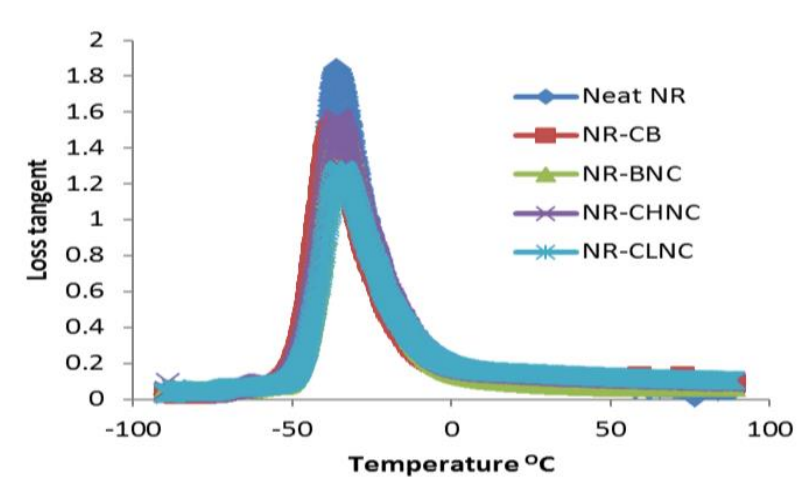

Figure 3: Effect of Temperature on Loss tangent of Composites

\subsection{Effect of Temperature and Particle Types on Loss Tangent ("tan delta")}

The effect of temperature on loss tangent (tan delta) of neat-NR, NR-CHNC, NR-BNC, NR-CLNC and NR-CB composites are shown in Figure 3. Loss tangent (tan delta) is the ratio of loss modulus to storage modulus; it is simply a measure of the energy lost and represents the mechanical damping or molecular internal friction of a viscoelastic configuration [5].

The result showed distinct single peaks for all samples. Two significant parameters corresponding to the $\mathrm{x}$ - and $y$ - axes of peak for various curves are of interest: the coordinate of the $\mathrm{x}$ - axis or abscissa is often used to locate the glass transition temperature $(\mathrm{Tg})$ of the material while the coordinate of y- axis also known as tangent delta maximum $\left(\tan \delta_{\max }\right)$ is used to locate the damping or loss factor [16]. The Tg obtained from these curves were $-35.84,-35.27,-34.61,-34.29$ and -37.30 ${ }^{\circ} \mathrm{C}$ for neat-NR, NR-CHNC, NR-BNC, NR-CLNC and NR$\mathrm{CB}$ respectively while their respective damping factors $\left(\tan \delta_{\max }\right)$ were $1.842,1.563,1.51,1.275$ and 1.518 . The damping or loss factor is a measure of the extent a viscoelastic material can damp or isolate vibration from external source. The Tg values composite of samples of cellulosic particles (NR-CHNC, NR-BNC and NR-CLNC) were observed to be slightly higher than that of the reference neat sample (neat-NR) compared to NR-CB signifying that the main rubber chain is stiffen by interacting with this cellulosic materials [16], this could be due to the polymeric nature of cellulosic materials. Natural rubber has been reported to be one of the polymer materials with the highest damping factor due to its inherent motion of the polyisoprene backbone [5]. The presences of other material in its matrix tend to reduce it damping capability. NR-CHNC however, gave the highest damping factors when compared to other composites samples (NR- CB, NR-BNC and NRCLNC). 
Table 3: Glass Transition Temperatures $\left(T_{g}\right)$ and Damping Values of Composites

\begin{tabular}{ccccc}
\hline Sample & $\begin{array}{c}\mathrm{T}_{\mathrm{g}} \text { from loss } \\
\text { modulus }\left({ }^{\circ} \mathrm{C}\right)\end{array}$ & $\begin{array}{c}\mathrm{T}_{\mathrm{g}} \text { from loss } \\
\text { tangent }\left({ }^{\circ} \mathrm{C}\right)\end{array}$ & $\begin{array}{c}\text { Damping factor tan } \\
\delta_{\max }\end{array}$ & $\begin{array}{c}\text { \% reduction in tan } \\
\delta_{\max }\end{array}$ \\
\hline Neat NR & -44.90 & -35.84 & 1.842 & \\
NR-CB & -44.99 & -37.30 & 1.518 & 17.8 \\
NR-BNC & -43.12 & -34.61 & 1.510 & 18.0 \\
NR-CHNC & -43.61 & -35.27 & 1.563 & 15.1 \\
NR-CLNC & -42.53 & -34.29 & 1.275 & 30.1 \\
\hline
\end{tabular}

The general reduction of damping factor $\left(\tan \delta_{\max }\right)$ with the introduction of filler as indicated in table 3 is attributed to reduction in the amount of mobile polymer chains during glass transition.

\section{CONCLUSIONS}

The dynamic mechanical properties of crosslinked natural rubber composites separately reinforced with $25 \mathrm{pphr}(18 \% \mathrm{wt}$ ) of cellulosic particles (from coconut husk, bamboo and cotton linter) and carbon black have been studied and compared with that of reference neat rubber. All samples were found to obey the expected theoretical trends of storage modulus versus temperature, loss modulus versus temperature and loss tangent versus temperature. However composite prepared from coconut husk cellulosic particles demonstrated superior properties in all cases.

\section{ACKNOWLEDGEMENT}

The authors gratefully acknowledge polymer characterization laboratory, Cochin University of Science and Technology, Kochi Kerala India, for the use of their facilities.

\section{REFERENCES}

[1] Verma, D., Gope, P. C., Shandilya, A., Gupta, A. and Maheshwari, M.K. "Coir Fibre Reinforcement and Application in polymer composites", Journal of Material and Enviromental Science, Vol. 4, Number 2, pp. 263-270, 2013.

[2] Rassiah, A., Sin, T. W. and Ismail, M. Z. "A study on flexural and water absorption of surface modified rice husk flour/E-glass polypropylene hybrid composites", Journal of Material Science and Technology, Vol. 152, pp. 1-10, 2016.

[3] Santos, F. A., Iulianelli, G. C. V. and Tavares, M.I.B. "The use of cellulose nanofillers in obtaining polymer nanocomposites: properties, processing, and applications", Journal of Materials Sciences and Applications, Vol.7, pp. 257-294, 2016.

[4] Robert, J. Y. and Peter, A. L. Introduction to Polymers. London: CRC Press, Taylor \& Francis group, 2012.
[5] James, C.G. and Ronald, A.L. Engineering Design with Polymers and Composites. New York: CRC Press Taylor \& Francis Group, 2012.

[6] Dung, T.A., Nhan, N. T., Thuong, N. T., Viet, D. Q., Tung, N. H., Nghia, P. T., Kawahara, S. and Thart, T. T. "Dynamic mechanical properties of Vietnam modified rubber via grafting with styrene". Journal of Science and Technology, Vol. 2017, pp. 1-8, 2017.

[7] Hans, A. S. "Conformational entropy contributions of blend of miscible polymers". Journal of Research of the National Institute of Standard and Technology, Vol.102, Number 2, pp. 229-237, 1997.

[8] Adedigbe, A. A., Selvin, P. T., Mamdouh, A. A., De, S. K., Srin, B ., Basfar, A. A., and Muataz, A. A. Natural rubber nanocomposites with functionalized carbon nanotubes; mechanical, dynamic mechanical and morphological studies. Journal of Applied Science, Vol.125, 51, pp. 7684, 2011.

[9] South, J. T. "Mechanical properties and durability of natural rubber ". Ph.D Thesis, pp. 34-60, 2001

[10] Visakh, P. M., Sabu, T., Kristiina, O. and Aji P. M. "Crosslinked natural rubber nanocomposites reinforced with cellulosewhiskers isolated from bamboo waste: Processing and mechanical/thermalproperties". Journal of Composites Part A Applied Science and Manufacturing, Vol. 43, pp. 735-743, 2012.

[11] Najidha, S., Predeep, A. and Saxana, N.S. Dynamic mechanical properties of natural rubber polyaniline composites". AIP Conference Proceedings, 2001.

[12] Adel, R. K., Shuna, C., Mohini, S. and Abdullah, A. "Mechanical, thermal and morphological properties of nanocomposites based on polyvinyl alcohol and cellulose nanofibre from Aloe vera rind". Journal of Nanomaterials, Vol. 2014, pp. 17, 2014.

[13] Oboh, J. O., Okafor., Kovo, A. S. and Abdulrahman, A. S. "Investigation of eco-friendly cellulosic nanoparticles potentials as reinforcement agents in the production of natural rubber composites". 
Nigerian Journal of Technology, Vol. 36, Number 4, pp. 1078-1087, 2017.

[14] Serge, R. and Fernand, P. "State of the Art Manufacturing and Engineering of Nanocellulose: A Review of Available Data and Industrial Applications'. Journal of Biomaterials and Nano Biotechnology, Vol. 1, No 4, pp. 165 - 188, 2013.

[15] Dan, G., Guoxin, X. and Jianbin, L. "Mechanical properties of nanoparticles: Basis and application". Journal of Physics and Applied Physics, Vol. 47, pp. 1-26, 2014.

[16] Zhang, C., Yidan, T., Turng, J. L. and Clemons, C.R.S. "Thermal and mechanical properties of rubber composites reinforced with cellulose nanocrystals from Southern Pine". Advances in Polymer Technology, pp. 21448-21455, 2014.

[17] Lee, K.-Y., Aitomaki, Y., Berglund, L. A., Oksman, $\mathrm{K}$. and Bismarck, A. "On the use of nanocelluluse as reinforcement in polymer matrix composites". Elsevier Journal of Composite Science and Technology, Vol.105, pp. 15-27, 2014.

[18] Janusz, D. and Paulina. P. A. “Comparative study on selective properties of Kraft lignin-natural rubber composites containing different plasticizers", Iran Polymer Journal, Vol.26, pp. 453-466, 2017.

[19] Czajka, M. "Thermoplastic graphene composites for mechanical, thermal stability and conduction applications" Ph.D thesis, pp 63-66, 2016. 